\title{
Term Infant
}

National Cancer Institute

\section{Source}

National Cancer Institute. Term Infant. NCI Thesaurus. Code C89333.

A newborn infant greater than or equal to 37 weeks, 0 days and less than or equal to 41 weeks, 6 days gestational age. 